\title{
DETERMINANTS OF FAMILY PLANNING AMONG MARRIED PEOPLE IN LAGOS-STATE
}

\author{
Alade Folasade Adesola (Ph.D) \\ Ekiti State University, Ado-Ekiti \\ Nigeria.
}

\begin{abstract}
The study examined the determinants of family planning among married people in Lagos state. The research design was the descriptive research of the survey type and the instrument used was a questionnaire titled "Perception of Family Planning among Married People." The population was all married people in Lagos state and the sample consisted 519 subjects selected through stratified sampling. One research question was raised and one hypothesis formulated to guide the study. This was tested at 0.05level of significance. Data collected were analysed using simple percentage and correlation matrix. The result of the analysis showed that all the determinants of family planning correlated significantly with married peoples' perception of family planning except child spacing with moderate relationship. Based on the findings, it was recommended that women should be encouraged through enlighten programme by government or health facilitators on the benefits of child spacing.
\end{abstract}

\section{Keywords: Contraceptives, marital satisfaction, sexual satisfaction, child spacing. Introduction}

Family planning is a process of controlling the number of children among couples. It is a lifesaver for millions of women and children in both developing countries including Nigerian and it is one of the most cost-effective health interventions. Family planning, according to Smith, Ashford, Gribble and Clifton (2009) increases survival, improves the health of millions of people and helps achieve national goals.

Family planning helps women to avoid unwanted pregnancies, illegal abortions and child bearing that will threaten their own personal health and that of the children. Family planning involves two concepts - contraceptive use and family planning services which is used by couples to bring about healthy sexual relationships among them without fears of unwanted pregnancies and sexually transmitted infections (Osakinle, 2003).

Ringheim and Gribble (2009) and Lordson (2012) further shed light on the role of the two concepts. The later opines that family planning can be said to be child spacing. He also believes it is a practice whereby prescribed orthodox medicines are used to prevent pregnancy while the previous child grows and the mother's body system recover sufficiently. Ringheim and Gribble (2009) also noted that contraception helps individual to choose when to have children, prevents unintended pregnancies, averts maternal and child deaths and prevents abortions.

Recent researches have indicated that family planning increases survival, improves the health of millions of people and helps achieve national goals. In "Return of the Population Growth Factor" (2009), it is believed that family planning can contribute to nearly all the goals outlined in the United Nation's Millenium Development Goals (MDGs) including reducing poverty and hunger, promoting gender equity and empowering women, reducing child mortality, improving maternal health, combating HIV/AIDS, and ensuring 
environmental sustainability. World Health Organisation (2007) also noted that family planning can help women wait at least two years before trying to become pregnant again, thereby reducing newborn, infant and child deaths significantly. In the same vein, Collumbien, Gerressu and Cleland (2004) are of the opinion that family planning could help prevent as many as one in every three maternal deaths by allowing women to delay motherhood, space births, avoid unintended pregnancies and abortions and stop childbearing when they have reached their desired family size.

Traditionally, Nigerians have recognised the need for spacing births. For example, abstinence while breastfeeding has been widely practiced in Nigeria in the olden days and according to Wolf and Abubukar (2008), it is still practiced in Nigeria across the northern Nigeria as a method of child spacing. Nnaocha (2002) observed that traditional ways used to prevent pregnancy in the olden days include prolonged lactation, post-natal and sexual abstinence and polygamy, that is, husband pressure for intercourse is reduced because of too many wives. Other methods include charms/armlets and herbs. With the increased population and diseases as stated by Lordson (2012), the traditional ways have become obsolete and modern family planning methods for child spacing have been adopted.

With the economic state of the Nation, couples begin to face unwanted pregnancies. Of the 210 million pregnancies occurring each year, according to W.H.O (2007), nearly 80 million are unintended. Unintended pregnancy is a primary reason for aborton. Each year, approximately 42 million women decide they cannot continue their pregnancies and seek abortions. An estimated 20 million of those abortions are performed either by persons lacking the necessary skills or in an environment lacking the minimal medical standards, or both resulting in nearly 67,000 deaths annually.

The family is the basic unit of the community and of reproduction. The national population is largely influenced by the individual family's reproductive behaviour. Hence, the impact of population will be felt at both family and national levels. At the family level, the greatest effect of high fertility is on the health of mothers and children. Studies have shown the risk of maternal and infant illness and death is highest in four specific types of pregnancies' before the age of 18 and 35, pregnancies less than two years apart and after the fourth birth, all of which are prevalent here (Document of the World Bank, 1993).

In Nigeria, marital satisfaction is usually based on childbearing. Owuamanam (1997) observed that childbearing is greatly valued and stands out as a major expectation of marriage in Nigeria. She stressed further that many marriages, if not all appear to be controlled more for childbearing than for other reasons because couples want children who will take over from them when they die but when this expectation fails to be realised, unhappiness comes into the marriage.

Sexual satisfaction has no doubt plays important role in marital satisfaction among couples. Every individual is a sexual being and one of the reasons marriage is instituted is for sexual intimacy. Adesanya (2002) observed that the biological function of intercourse is to assure perpetuation of the species, but beyond this, in modern marriage, coitus can serve to the husband and wife a sense of emotional warmth, a release from tension and at times, a delightful diversion, no wonder some couples have taken to family planning methods in other to prevent the occurrence of pregnancies.

In a survey conducted by Heiman, Long, Smith, Fisher and Sand (2011) on "Sexual Satisfaction and Relationship Happiness in Midlife and Older Couples in Five Countries", it was found out among others that women selected committed partners based on relationship quality more than sexual satisfaction and that, for women in childbearing years, dealing with avoiding pregnancies or having children among other life stressors, all take a toll on sexual satisfaction. Therefore, to enjoy healthy sexual relationship, couples need to adopt family planning services to allay fears of unwanted pregnancies. It is against this background that 
the researcher would like to investigate the determinants of family planning and its perception among married people in Lagos State.

One research question and one hypothesis were raised to guide the study.

Research Question

How do married people perceive family planning in Lagos State?

\section{Research Hypothesis}

There is no significant relationship among the determinants of family planning and its perception among married people in Lagos State.

Methodology

A descriptive research design of the survey type was adopted in this study. This was considered appropriate because it carefully observes and records information as it naturally occurs.

\section{Population}

The population consisted all married people in Lagos State.

\section{Sample and Sampling Technique}

The sample size was made up of 519 married people cutting across Lagos State. Simple random sampling technique was used to select five local government areas from two provinces of the population while stratified sampling technique was used to select the respondents consisting of male and female married people from churches, mosques, hospitals, local government areas.

\section{Research Instrument}

A self-designed instrument was used to generate data for the study. The instrument had section ' $A$ ' which was on personal data while section ' $B$ ' had 40 items on various factors that can influence family planning. A panel of guidance counsellors and psychologists established its face and content validities. The test re-test method was done on 20 married people in Ekiti that were not part of the samples at the interval of two weeks. Pearson Product Moment Correlation formula was used to analyse the result. The reliability coefficient of 0.77 was obtained which was found to be reliable for the study.

\section{Data Analysis}

Inferential Statistics of Correlation Matrix and Simple Percentage were used to analyse the data. The hypothesis was tested at 0.05 level of significance.

\section{Results and Discussion}

The result of the analysis is presented below.

\section{Research Question}

How do married people perceive family planning in Lagos State?

The question was answered using percentages of responses to show the favourable and unfavourable perception of married people to family planning as shown in table 1.

Table 1 Perception of married people on family planning.

\begin{tabular}{|c|c|c|c|c|}
\hline Family Planning & \multicolumn{2}{|c|}{ Favourable (\%) } & \multicolumn{2}{|c|}{ Unfavourable (\%) } \\
\hline Perception of married people & $\mathbf{N}$ & $\%$ & $\mathbf{N}$ & $\%$ \\
\hline & 314 & 60.5 & 205 & 39.5 \\
\hline
\end{tabular}

$\mathrm{N}=519$

Table 1 shows $60.5 \%$ of the respondents have favourable perception of family planning while $39.5 \%$ have unfavourable perception. 
Responses of married people to strongly agree and disagree were used to determine favourable perceptions while strongly disagree and agree were used to determine unfavourable perception. The negative stated questions were reversed.

\section{Research Hypothesis}

There is no significant relationship among the determinants of family planning and its perception among married people in Lagos State.

Table 2: Correlation Matrix on Determinants of Family Planning among Married People in Lagos State

\begin{tabular}{|l|l|l|l|l|l|l|}
\hline & $\begin{array}{l}\text { Family } \\
\text { Planning }\end{array}$ & $\begin{array}{l}\text { Marital } \\
\text { Satisfaction }\end{array}$ & $\begin{array}{l}\text { Sexual } \\
\text { Relationship }\end{array}$ & $\begin{array}{l}\text { Child } \\
\text { Spacing }\end{array}$ & $\begin{array}{l}\text { Size of } \\
\text { the } \\
\text { Family }\end{array}$ & $\begin{array}{l}\text { Societal } \\
\text { Value }\end{array}$ \\
\hline Family Planning & 1.000 & & & & & \\
\hline Marital Satisfaction & $.747^{*}$ & 1.000 & & & & \\
\hline Sexual Relation & $.727^{*}$ & $.516^{*}$ & 1.000 & & & \\
\hline Child Spacing & $.353^{*}$ & $.264^{*}$ & .159 & 1.000 & & \\
\hline Size of the Family & $.348^{*}$ & .187 & $.229^{*}$ & $.239^{*}$ & 1.000 & \\
\hline Societal needs & $.723^{*}$ & $.460^{*}$ & $.350^{*}$ & $.267^{*}$ & $.206^{*}$ & 1.000 \\
\hline
\end{tabular}

*Correlation is significant at 0.05 level

Table 2 showed the interrelationships among the determinants of family planning among married women in Lagos State which vary from strong to weak, although positive. Analysis of the correlation revealed that all the identified factors influencing the perception of family correlated significantly with their perception of family planning, that is, perception of family planning has high positive relationship with marital satisfaction $(\mathrm{r}=.747, \mathrm{P}<0.05)$, with sexual relation $(.727, \mathrm{P}<0.05)$ with size of the family $(\mathrm{r}=.348, \mathrm{P}<0.05)$, with societal value $(\mathrm{r}=.723, \mathrm{P}<0.05)$ and moderate relationship with child spacing $(\mathrm{r}=.353, \mathrm{P}<0.05)$.

The inter-relationships among the determinants showed that marital satisfaction has moderately high relationship with sexual relation $(\mathrm{r}=.516, \mathrm{P}<0.05)$, moderate positive relationship between child spacing and societal needs $(r=.264, .460, \mathrm{P}<0.05)$ accordingly but weak positive relationship with size of the family $(\mathrm{r}=.187, \mathrm{P}<0.05)$. Sexual relation has moderate relationship with size of the family $(\mathrm{r}=.229, \mathrm{P}<0.05)$ and societal value $(\mathrm{r}=.460$, $\mathrm{P}<0.05)$ but has positive significant relationship with child spacing $(\mathrm{r}=.264, \mathrm{P}<0.05)$. The relationship between child spacing and size of the family $(\mathrm{r}=.239)$ and societal value $(\mathrm{r}=$ .267) is moderate and positive. Similarly, there exist significant relationship between size of the family and societal value $(\mathrm{r}=.206, \mathrm{P}<0.05)$.

\section{Discussion}

The study examined the determinant of family planning among married people in Lagos State. It further determined how married people perceived family planning. The research question sort to know how married people perceived family planning and the result showed that majority of them have favourable perception towards it. This correlates with the positive value some researchers place on family planning. Smith, Ashford, Gribble and Clifton (2009) believed that family planning increases survival, improves the health of millions of people and helps achieve national goal. Corroborating this, Ringheim and Gribble (2009) noted that contraception helps individual to choose when to have children, prevents unintended pregnancies, averts maternal and child deaths and also prevents abortions.

The research hypothesis states there is no significant relationship among the determinants of family planning and its perception among married people in Lagos State. The null hypothesis was rejected. It is evident from researches that all factors which include size of the family, societal value, sexual and marital satisfaction have significant relationships with family 
planning except child spacing which had a moderate relationship. Osakinle (2003) observed that family planning services help couples to bring about healthy sexual relationships without fear of unwanted pregnancies. In the same vein, World Health Organisation (2007) also noted that family planning can help women wait at least two years before trying to become pregnant again, thereby reducing newborn, infant and child deaths significantly.

Collumbien, Gerrussu and Cleland (2004) are also of the opinion that family planning could prevent as many as one of in every three maternal deaths by allowing women to delay motherhood, space births, avoid unwanted pregnancies and abortions and stop child bearing when they have reached their desired family size.

\section{Conclusion}

It was revealed from the findings that all determinants of family planning correlated significantly with married peoples' perception of family planning, that is, perception of family planning has high positive relationship with the determinants except a moderate relationship with child spacing.

\section{Recommendations}

Based on the conclusion of the findings, it was recommended that women should be encouraged through enlighten programmes by government or health facilitators on the benefits of child spacing.

Counsellors, especially in marital counselling should counsel the married people on the importance of family planning as an instrument of child spacing which in turn could enhance sexual and marital satisfaction.

\section{References}


Adesanya, S. A (2002). Correlates of marital stability among couples in south western Nigeria. Unpublished Ph.D thesis. University of Ado-Ekiti.

Collumbien M, Gerressu M, Cleland J, "Non-Use and Use of Ineffective Methods of Contraception," in Comparative Qualification of Health Risks: Global and Regional Burden of Disease Attributable to Selected Major Risk Factors, ed. Majid Ezzati et al. (Geneva: World Health Organization,2004): 1255-1320

Heiman, J. R, Long J. S, Smith S. N, Fisher A, W, Sand M. S (2011). Sexual Satisfaction and Relationship Happiness in Midlife and Older Couples in Five Countries. Spinger Science + Business Media, LLC.

Lordson J. (2012). Pregnancy, Child Spacing and Family Planning: Blueprint Newspaper. http://blueprint.com

Nnaocha, G. I (2002). Contraception. A violation of the Sacredness of Human Sexuality. Unpublished thesis, Owerri.

Osakinle, E. O (2003). The Dynamics of Sexual Behaviour of Female Students in the south western part of Nigerian Universities. A Ph. D Dissertation in the Faculty of Education,

University of Ado-Ekiti, Nigeria.

Owuamanam T. O (1997). Marital Satisfaction and Multidimensional Factors among Igbo people in Imo-State, Nigeria. Unpublished $\mathrm{Ph}$. D thesis. Ondo State University, AdoEkiti.

Return of the Population Growth Factor-Its Impact Upon the Millenium Development Goals, Report of Hearings by the All Party Parliamentary Group on Population, Development, and Reproductive Health, January (2007)

Ringheim K and Gribble J (2009). Population Reference Bureau. Washington D C, USA.

Smith R, Ashford L, Gribble J, Clifton D (2009). Family Planning Saves Lives $4^{\text {th }}$ ed. Population Reference Bureau. Washington, D C, USA.

Udjo, 1987. In Oguntimehin O. Rosemary (1989) A survey of the reactions of female residents of Bariga area of Lagos to family planning. Unpublished thesis, University of Lagos.

WHO (2003), Unsafe Abortion-Global and Regional Estimates of the Incidence of Unsafe Abortion and Associated Mortality.

WHO (2007), Unsafe Abortion-Global and Regional Estimates of the Incidence of Unsafe Abortion and Associated Mortality in $2003,5^{\text {th }}$ ed.

Wolf M and Abubakar A (2008) "Literature Review: Islam and Family Planning with a special emphasis on Northern Nigeria”. Family Health International, Research Triangle Park, N C Part I. 